\title{
The Effect of Educational Intervention on Knowledge and Attitudes toward Sexually Transmitted Infections on a Sample of Egyptian Women at Primary Care Level
}

\author{
Tarek Tawfik Amin ${ }^{1}$, Yasmine Samir Galal ${ }^{1}$, Dina Samy Shaheen ${ }^{2}$, Marwa Rashad Salem ${ }^{1 *}$ \\ ${ }^{1}$ Department of Public Health and Community Medicine, Faculty of Medicine, Cairo University, Egypt; ${ }^{2}$ Department of Internal \\ Medicine, Faculty of Medicine, Cairo University, Egypt
}

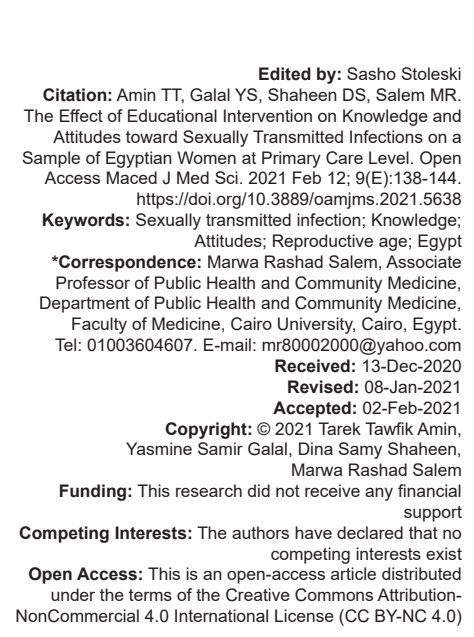

\begin{abstract}
OBJECTIVES: The current study was conducted to assess the effect of an educational intervention on knowledge status and attitudes toward sexually transmitted infections (STIs) in a sample of women in reproductive age.

METHODS: One group quasi-experimental study was conducted at one primary health care center in Egypt; included 200 women selected by systematic sampling method. Health education intervention was designed and implemented to fill the knowledge gap revealed in pre-test in relation to prevention, early detection and STIs treatment.

RESULTS: The results revealed that knowledge about types, modes of transmission and causative agents of STIs, symptoms and complications of STIs, and prevention and treatment increased in post-test $(p=0.001)$, with significant increase of total knowledge score in post-test $(p=0.001)$. The attitudes toward STIs were also improved at post-test compared to pre-test.

CONCLUSION: The study reflected the need for implementing educational programs to improve STIs' knowledge
\end{abstract} and increasing women's readiness for STIs screening.

\section{Introduction}

Sexually transmitted infections (STIs) have been recognized for years as a major public health problem especially in developing countries; with more than one million cases occurring daily worldwide and 500 million people living with curable STIs among adults aged 15-49 years [1]. However, reliable data on regional prevalence are limited and the best available estimates according to the World Health Organization indicated that about 10 million new cases occur annually in the Eastern Mediterranean Region [2]. In Egypt, the prevalence and incidence of STIs remained largely unknown because disease surveillance system has been markedly neglected [3].

Few countries in the EMR have developed a comprehensive national strategy for prevention and control of STIs, aiming for the achievement of the Millennium Development Goals and to prevention and control of HIV [4]. However, interventions are lacking evidence-based effective public health approaches, as recommended in the global control strategy. In 2015, the Egyptian government is paying great attention to achieve the Sustainable Development Goals. This is expressed in "Strategy for Sustainable DevelopmentEgypt Vision 2030." To be effective, national strategies should be translated into actions that reach communities, families, and individuals at grass roots [5].

In developing countries, STIs control programs often fail to achieve their goal due to the conservative nature of the societies shaped by the cultural, religious, and social taboos which leave women too shy to express their reproductive health needs or seek health services [6]. In addition, STIs are often left undiagnosed and untreated due to lack of knowledge on one hand and the deficiency of health care facilities providing appropriate and timely care on the other [7], [8].

In Egypt, there is paucity of studies assessed the knowledge status, the attitudes, and the safe sex practices for STIs prevention especially among those suffering health inequality namely women and adolescents [9]. Most of the available studies focused on HIV with negligence of other STIs or merely assessing their prevalence [10]. We hypothesized that an educational intervention about STIs may increase the knowledge of 
women in the reproductive age by at least $50 \%$ compared to the baseline level. Subsequently, the current study was conducted to assess the effect of an educational intervention on knowledge status and attitudes toward STIs in a sample of women in reproductive age attending a primary health care $(\mathrm{PHC})$ center in Egypt.

\section{Methods}

\section{Study design, period, and setting}

This study adopted a one group pre-posttest quasi-experimental design and it was carried out at a PHC in Giza Governorate. The study spanned over 6-month duration from August 2019 to February 2020.

\section{Study population and sampling}

Study population: Women aged 15-45 years who attended the PHC center seeking different health services including antenatal care, family planning, etc. Critically ill women were excluded from the study.

\section{Sample size}

Knowledge score was the continuous outcome in this study, sample size for before-after study (paired t-test) was used for calculation, with considering type I error of 0.05 , type II error $(\beta)$ of 0.20 , expected effect size of the educational intervention of at least $50 \%$ increment and proposed a standard deviation of the change $\left(\mathrm{S}^{\Delta}\right)$ in knowledge (the outcome) of 2.0 , where $\left(S^{\Delta}\right)$ equal to $\mathrm{S}\left(2\left(1-\mathrm{r}_{\text {within }}\right)\right)^{1 / 2}, \mathrm{~S}=$ the standard deviation of the outcome in the population of 0.5 , and $r=$ the within-subject correlation of the outcome of 0.8 [11]. A one group sample size of 128 women was required; adding a $20 \%$ increment for the possibility of non-response, a total of 154 women was the estimated sample size. Eligible women were selected randomly using systematic method using the $\mathrm{PHC}$ registries and those selected were personally approached and invited to participate. Of the 218 women approached, 200 agreed to participate.

\section{Study tools and data collection technique}

\section{Baseline assessment}

A pre-tested structured interview questionnaire was used to collect data from the study participants. It included four sections:

- Socio-demographic characteristics: Age, residence, marital status, education, occupation, and family income (in Egyptian pounds)

- $\quad$ STIs knowledge of study participants: A total of 21 items, 7 items addressed the causative agents and modes of transmission, 7 items covered the symptoms and complications, and another 7 for prevention and treatment of STIs. The questions formatted in closeended and multiple-choice options with true scored 1, while false and do not know scored 0 . Questions used in this section were adopted from the available literature [12], [13], [14] Sources of knowledge about STIs were also inquired using multiple options format

STIs related attitudes: Five questions were used to assess the participants' attitudes toward STIs; their need to receive counseling sessions and their readiness and willingness to get screened and treated for STIs (all scored as 1 for agree, and 0 for not sure or disagree, except one question where yes scored 1 , while not sure and not needed scored 0 ).

The same tool was used in the post-intervention phase to assess the change in the knowledge and attitudes of the participants.

The original language of the included items was English; they were translated to Arabic by two experts followed by back translation to English by other independent experts.

\section{Pilot testing}

The preliminary data collection form was tested on 26 women (attended a nearby $\mathrm{PHC}$ and beyond the sample size) to assess the clarity and comprehension of questions, and the time needed to answer the questionnaire. Originally, the data collection form composed of 28 items with reliability coefficient of 0.466 (Cronbach's alpha), following the removal of 7 items (assessing the signs of early infections, some other causative agents, and complications), the alpha coefficient increased to 0.656 ( $r$ coefficient were 0.671 , 0.551 , and 0.508 for types/modes of transmission, symptoms, and prevention, respectively).

\section{Intervention phase}

The health education sessions (Table 1) were in the form of PowerPoint presentations covering the Table 1: Summary of the standardized health education intervention about STls to women at reproductive age (15-45 years) at PHC, Giza, Egypt

\begin{tabular}{|c|c|}
\hline Overview & $\begin{array}{l}\text { Contents } \\
\text { - Pre-test (baseline assessment) } \\
\text { - Introduction to the session } \\
\text { - Orientation about the objectives and possible impact of the research }\end{array}$ \\
\hline Session I & $\begin{array}{l}\text { STIs awareness } \\
\text { - What are STIs? } \\
\text { - Symptoms and signs of STIs } \\
\text { - Risk factors for STIs } \\
\text { - Complications of STIs }\end{array}$ \\
\hline Session II & $\begin{array}{l}\text { Prevention, early detection, and treatment of STIs } \\
\text { - Prevention of STIs } \\
\text { - Screening of the most common STIs } \\
\text { - Treatment of STIs }\end{array}$ \\
\hline Session III & Recap and take home messages \\
\hline
\end{tabular}


knowledge gaps evolved from the baseline assessment in the pre-intervention phase regarding STIs. The content was adapted from the available literature [14].

The sessions were conducted over 4 consecutive days, in the form of group meetings each lasted from 30 to $45 \mathrm{~min}$ and including 50 participants using the same instructor and educational materials. Health education materials were designed and translated to Arabic language, simplified, modified to adopt the Egyptian culture and were then finally reviewed by the principal investigator and pretested to assess their clarity (Table 1 ).

\section{Post-intervention assessment}

Participants $(n=200)$ attended the sessions and responded to the pre-test questionnaire prior the educational intervention were contacted after 2 months (using their phone numbers) and invited to another interview at the center for a post-test. The post-test assessment was facilitated by the fact that women usually come back for follow-up and routine services in the same center. Out of the 200 women included in the pre-test and educational intervention, nine were lost and did not attend the interview; making a total of 191 participants in the post-test.

\section{Data management and statistical analysis}

Pre-coded revised data were entered into the Statistical Package of Social Science (SPSS) version 21.0 (SPSS Inc. IBM, U.S.A.). For categorical data frequencies and percentages were used for expression while for numerical data mean (median and interquartile range) and standard deviation were used. Comparison between pre-intervention and post-intervention data was performed using the McNemar test for qualitative data. Total knowledge score was computed for each group of questions where correct answers received one point while incorrect or do not know received nil. Total knowledge score was calculated for all knowledge questions (21 points), a $60 \%$ cutoff was used to indicate improved knowledge, 13 or more points were categorized as improved knowledge. Comparison between total pre- and post-knowledge scores was performed using the Wilcoxon's sign test. $p \leq 0.05$ was considered statistically significant.

\section{Ethical considerations}

The Ethical Review Committee at the Faculty of Medicine, Cairo University revised and approved the study protocol. Informed consent form was obtained after proper orientation regarding the study objectives, data confidentiality, as well the potential impact of the study on the health services. Women were informed of their right to withdraw from the study at any stage.

\section{Results}

The mean age of the included women $(n=200)$ was $31.13 \pm 8.12$ years, $95 \%$ of them were married and $79.5 \%$ were housewives, and $18 \%$ from rural areas. Sources of STIs knowledge: Health providers were the most common source of information (79\%), and others including newspapers and mass media campaigns $(5.5 \%)$ provided the least sources of information.

Baseline assessment showed that only $46 \%$ of participants (92/200) ever heard about STIs and only five STIs were mentioned: HIVIAIDS 90.2\%, syphilis $(30.4 \%)$, gonorrhea $(27.2 \%)$, hepatitis b virus (HBV) $(8.7 \%)$, and chlamydia $(2.1 \%)$. Following the educational sessions, awareness of STIs increased to $87.7 \%$ with widening of STIs spectrum, HIVIAIDS (95.8\%), syphilis (33.1\%), gonorrhea (27.1\%), and HBV (20\%), chlamydia $(4.2 \%)$.

Sexual contact is not the only means of transmission of STIs showed significant change from $42.4 \%$ in the pre to $77 \%$ in the post-intervention $(p=0.001)$, other modes of transmission included blood transfusion, contaminated syringes and from pregnant mother to her child increased from $33 \%$ in the pre-test to $96.3 \%$ in the post-test $(p=0.001)$. Participants in the post-test were more knowledgeable about the causative agents of STIs as they correctly identified that these include bacteria, viruses, parasites, and fungi (increased to $85.9 \%$ compared to $29.8 \%$ in the pre-test, $p=0.001$ ). The knowledge score (out of 7 points) increased from $1.9 \pm 2.3$ (median of 1.0 ) at the baseline to $5.7 \pm 1.1$ (median of 6.0) with three folds' increase between the pre- and post-intervention ( $p=0.001$ ) (Table 2).

Table 2: Correct responses of women at primary care about knowledge items of types, modes of transmission, and causative agents of STIs, Giza, Egypt

\begin{tabular}{|c|c|c|c|}
\hline \multirow[t]{2}{*}{ Knowledge items } & Pre-test $(n=200)$ & Post-test $(n=191)$ & $p$-value ${ }^{*}$ \\
\hline & No. (\%) & No. $(\%)$ & \\
\hline $\begin{array}{l}\text { STDs are solely transmitted through } \\
\text { sexual contact: }(F)\end{array}$ & $81(42.4)$ & $147(77 \%)$ & 0.001 \\
\hline $\begin{array}{l}\text { Modes of transmission of sexually } \\
\text { transmitted diseases (STDs): } \\
\text { Multiple options }\end{array}$ & $63(33.0)$ & $184(96.3)$ & 0.001 \\
\hline $\begin{array}{l}\text { Causative agents of STDs: Multiple } \\
\text { options }\end{array}$ & $57(29.8)$ & $164(85.9)$ & 0.001 \\
\hline $\begin{array}{l}\text { STDs are all caused by the same } \\
\text { organism: }(F)\end{array}$ & $29(15.2)$ & $147(77.0)$ & 0.001 \\
\hline $\begin{array}{l}\text { Those infected with HIV can be } \\
\text { infected with another sexually } \\
\text { transmitted disease: }(T)\end{array}$ & $20(10.5)$ & $105(55.0)$ & 0.001 \\
\hline $\begin{array}{l}\text { HIV is transmitted only through } \\
\text { sexual contact: }(T)\end{array}$ & $56(29.3)$ & 179 (93.7) & 0.001 \\
\hline $\begin{array}{l}\text { Hepatitis } C \text { virus is transmitted only } \\
\text { through infected blood: }(T)\end{array}$ & $55(28.8)$ & 169 (88.5) & 0.001 \\
\hline \multicolumn{4}{|l|}{ Knowledge score (out of 7 points) } \\
\hline Mean $\pm S D$ & $1.9 \pm 2.3$ & $5.7 \pm 1.1$ & $0.001^{\dagger}$ \\
\hline Median (IQR) & $1.0(0-4)$ & $6.0(5-6)$ & \\
\hline Mean rank & 20.22 & 92.18 & \\
\hline
\end{tabular}

Common symptoms of STIs including vaginal discharge, genital itching, painful micturition, lower abdominal pain, and dyspareunia were low at the baseline assessment (33\%) compared to $96.8 \%$ in posteducational intervention $(p=0.001)$. Of the included 
women, $20.4 \%$ in the pre-test correctly identified that STIs can occur without symptoms, doubled in the post-test $(40.8 \%),(p=0.001)$. Recognizing the early symptoms of HIV infection including elevated body temperature, sore throat, severe headache, and weight loss was significantly improved following educational sessions compared to the baseline level (post-test $86.9 \%$ compared to $29.3 \%$ at baseline, $p$ $=0.001)$. Complications of STIs including infertility, abortions, stillbirths, blindness in children, and cancer cervix, the knowledge of which was also improved with correct responses increased from $16.8 \%$ in pretest to $99 \%$ in the post-test $(p=0.001)$. Misconception including the false believe that STIs lead to health problems that are more serious in men than women improved from 37.2 to 90.6 in the post-test $(p=0.001)$. The knowledge score (out of 7 points) increased of more than 3 folds from $1.4 \pm 2.0$ (median of 1.0) at the baseline to $5.3 \pm 1.5$ (median of 6.0 ) at the post-test ( $p$ $=0.001)$ (Table 3).

Table 3: Correct responses of women at primary care about knowledge items of symptoms and complications of STIs, Giza, Egypt

\begin{tabular}{|c|c|c|c|}
\hline Knowledge items & Pre-test $(n=200)$ & Post-test ( $\mathrm{n}=191)$ & $p$-value \\
\hline & No. $(\%)$ & No. $(\%)$ & \\
\hline $\begin{array}{l}\text { Symptoms of STDs } \\
\text { include: ----- options }\end{array}$ & $63(33.0)$ & $185(96.8)$ & 0.001 \\
\hline $\begin{array}{l}\text { A person infected with STIs could } \\
\text { have no symptoms: }(\mathrm{T})\end{array}$ & $39(20.4)$ & $78(40.8)$ & 0.001 \\
\hline $\begin{array}{l}\text { Early symptoms of HIV infection } \\
\text { include: Options }\end{array}$ & $56(29.3)$ & $166(86.9)$ & 0.001 \\
\hline $\begin{array}{l}\text { Complications of STDs include: } \\
\text { Options }\end{array}$ & $32(16.8)$ & $189(99.0)$ & 0.001 \\
\hline $\begin{array}{l}\text { Gonorrhea can cause repeated } \\
\text { urinary tract infections: }(T)\end{array}$ & $15(7.9)$ & $123(64.4)$ & 0.001 \\
\hline $\begin{array}{l}\text { STDs lead to health problems } \\
\text { more serious for men than } \\
\text { women: }(F)\end{array}$ & $18(9.4)$ & $121(62.8)$ & 0.001 \\
\hline $\begin{array}{l}\text { STDs represent a serious threat to } \\
\text { pregnant women: }(T)\end{array}$ & $42(22.0)$ & $158(82.7)$ & 0.001 \\
\hline \multicolumn{4}{|l|}{ Knowledge score (out of 7 points): } \\
\hline Mean $\pm S D$ & $1.4 \pm 2.0$ & $5.3 \pm 1.5$ & $0.001^{\ddagger}$ \\
\hline Median (IQR) & $1.0(0-2)$ & $6.0(4-6)$ & \\
\hline Mean rank & 28.19 & 93.40 & \\
\hline
\end{tabular}
infection.

Of the included women, $72.8 \%$ correctly identified that male condoms can reduce the risk of STIs compared to $31.9 \%$ at the baseline $(p=0.001)$. False beliefs about the presence of protective vaccines against hepatitis $\mathrm{c}$ and HIV were significantly improved following the educational intervention. Women in the

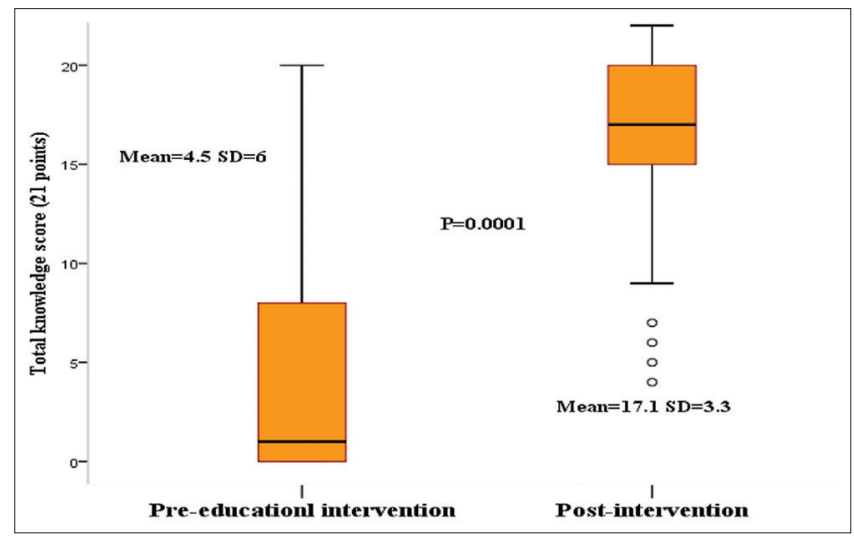

Figure 1: Total knowledge scores about STIs of the study group (pretest and post-test). $p$ value: Wilcoxon's Sign Rank test post-intervention were more knowledgeable regarding STIs prevention and treatment as they correctly stated that $\mathrm{HBV}$ can be prevented by vaccination, increased to $81.2 \%$ in the post-test compared to $25.7 \%$ at baseline ( $p=0.001)$ and that gonorrhea, chlamydia, and syphilis are curable STIs. The knowledge score (out of 7 points) increased by 4 folds from $1.3 \pm 2.1$ (median of 1.0) to $5.3 \pm 1.6$ (median of 6.0$)$ in the post-test $(p=0.001)$ (Table 4). Total knowledge score was calculated $43.3 \%$ of the participants had improved knowledge of $60 \%$ cutoff level.

Figure 1 shows significant improvement of the total knowledge score from $4.6 \pm 6.0$ (median of 1) in the pre-intervention to17.1 \pm 3.3 (median of 17 ), of more than 3.7 folds in the post-test $(p=0.001)$.

\section{Attitude toward STIs}

In the post-intervention, more women believed that both partners are responsible for preventing transmission of STIs ( $89 \%$ vs. $31.9 \%, p=0.001)$ and expressed their need to have counseling sessions (81.2\% compared to $25.7 \%$ in the pre, $p=0.001)$.

Table 4: Correct responses of women at primary care about knowledge items of prevention and treatment STIs, Giza, Egypt

\begin{tabular}{|c|c|c|c|}
\hline Knowledge items & Pre-test $(n=200)$ & Post-test $(n=191)$ & $p$-value ${ }^{*}$ \\
\hline & No. (\%) & No. (\%) & \\
\hline $\begin{array}{l}\text { Using condom can reduce the risk of } \\
\text { infection with STDs: }(T)\end{array}$ & $61(31.9)$ & $139(72.8)$ & 0.001 \\
\hline $\begin{array}{l}\text { There is a vaccine that can protecting } \\
\text { against hepatitis } B:(T)\end{array}$ & $49(25.7)$ & $155(81.2)$ & 0.001 \\
\hline $\begin{array}{l}\text { There is a vaccine that can protecting } \\
\text { against hepatitis } C:(F)\end{array}$ & $14(7.3)$ & $154(80.6)$ & 0.001 \\
\hline $\begin{array}{l}\text { There is a vaccine that can protecting } \\
\text { against HIV: }(F)\end{array}$ & 38 (19.9) & 177 (92.7) & 0.001 \\
\hline Gonorrhea is a curable infection: $(\mathrm{T})$ & $28(14.7)$ & $131(68.6)$ & 0.001 \\
\hline Chlamydia is a curable infection: $(T)$ & $25(13.1)$ & $129(67.5)$ & 0.001 \\
\hline $\begin{array}{l}\text { Syphilis can be treated and } \\
\text { cured: }(T)\end{array}$ & $28(14.7)$ & 122 (63.9) & 0.001 \\
\hline \multicolumn{4}{|l|}{ Knowledge score (out of 7 points) } \\
\hline Mean $\pm S D$ & $1.3 \pm 2.1$ & $5.3 \pm 1.6$ & $0.001^{\S}$ \\
\hline Median (IQR) & $1.0(0-2)$ & $6.0(4-7)$ & \\
\hline Mean rank & 37.80 & 91.50 & \\
\hline
\end{tabular}

STI: Sexually transmitted infection

Furthermore, more participants in the post-test expressed their readiness for STIs screening (80.6\% compared to $22 \%$ in pre-test, $p=0.001$ ) (Table 5 ).

Table 5: Favorable attitude items of women at primary care toward STIs, pre- and post-educational intervention, Giza, Egypt

\begin{tabular}{|c|c|c|c|}
\hline \multirow[t]{2}{*}{ Attitude items } & Pre-test $(\mathrm{n}=200)$ & Post-test $(n=191)$ & $p$-value $e^{e}$ \\
\hline & No. $(\%)$ & No. (\%) & \\
\hline $\begin{array}{l}\text { Both partners are responsible } \\
\text { for prevention of transmission } \\
\text { of STDs: (agree): Agree-not } \\
\text { sure-disagree }\end{array}$ & $63(31.9)$ & $170(89.0)$ & 0.001 \\
\hline $\begin{array}{l}\text { I need counseling sessions } \\
\text { about STDs: (Yes): Yes-not } \\
\text { sure-not needed }\end{array}$ & $49(25.7)$ & $155(81.2)$ & 0.001 \\
\hline $\begin{array}{l}\text { I am ready to be screened } \\
\text { for STDs: (agree): Agree-not } \\
\text { sure-disagree }\end{array}$ & $42(22.0)$ & $154(80.6)$ & 0.001 \\
\hline $\begin{array}{l}\text { I am willing to be treated for } \\
\text { STDs if diagnosed: (agree): } \\
\text { Agree-not sure-disagree }\end{array}$ & $56(29.3)$ & $166(86.9)$ & 0.001 \\
\hline $\begin{array}{l}\text { Sexual health and STDs } \\
\text { prevention should be included } \\
\text { in school curricula: (agree): } \\
\text { Agree-not sure-disagree }\end{array}$ & $15(7.9)$ & $123(64.4)$ & $0.001^{*}$ \\
\hline
\end{tabular}




\section{Discussion}

This pre-post study revealed a low level of knowledge about the modes of transmission, symptoms, complications, prevention, and treatment of STIs, where most of the participants had heard about AIDS but their awareness of other STIs was significantly low. These findings are consistent with the results of studies in many developing countries [15], [16]. Inadequate knowledge and the prevailing misconceptions about STIs and their treatment have led them to be the silent killers among the women population especially with widespread publicity about the importance of AIDS and negligence of other STIs [14].

This study showed a significant improvement in the level of knowledge about modes of transmission of STIs and HIV in the post-intervention phase. Sakha et al. [16], in their study to assess the effect of an educational intervention on knowledge about and attitude toward STIs, found that most women had a good level of knowledge before the intervention about the modes of transmission of HIV and STIs through the blood and through sharing needles. However, knowledge about other modes of transmission such as mother to child, unusual sexual contact, and infected mother's milk increased significantly after the intervention [16].

Sharma and Sherkhane [17] reported that blood transfusion was the most common mode of contracting STIs, followed by sexual contact and needle prick injury, and about half of their participants thought that infections could spread from mother to child. Misconceptions about STIs transmission weaken the motivation to adopt safer sexual behavior and strengthen stigmatization against people for that they may be discouraged from accessing healthcare services [17]. This study reported that few participants knew that microorganisms such as bacteria and viruses cause STIs, in agreement with the findings of another study conducted by Nawagi et al. [18].

Consistent with a study conducted in Southern Iran [17], the present study revealed a significant improvement of knowledge after the intervention in relation to the most common symptoms of STIs. Lan et al. [6] found a relatively low proportion of women who correctly stated the suspected symptoms of STIs, vaginal itching by only $16 \%$, followed by abnormal vaginal discharge by $9.5 \%$, lower abdominal pain and dyspareunia were rarely mentioned, while Norbu et al. reported higher levels of knowledge regarding symptoms of STIs [19].

Poorlevels of knowledgeaboutthe complications of STIs were reported by some studies [19], in this study, there was a significant improvement of knowledge about the complications of STIs following educational intervention.
Insufficient knowledge about STIs prevention and the value of partner's treatment may result in underestimating the risks of unsafe sex. Condom use is considered the single most efficient method for reducing sexual transmission of both HIV and STIs [8]. In this study, women's knowledge was poor prior the intervention. In a study conducted by Lan et al. [6] low percentage of women correctly identified the methods of prevention of STIs [6]. In contrast, in a study conducted in Uganda, knowledge about methods of prevention of STIs transmission were high (92.3\%), condom use being the most frequently reported method by nearly $50 \%$ of participants [18].

Treatment of STIs is a cost-effective investment for countries, both as means of reducing the serious morbidity caused by such infections and as an intervention to prevent HIV [20]. In the present study, only $14.7 \%$ correctly mentioned that gonorrhea and syphilis are curable diseases. A similar finding was reported by Lan et al. [6].

Low level of knowledge about STIs before the intervention in the current study can be explained partially by the unavailability of a national plan to provide outreach and educational programs targeting the general population especially women of reproductive age where most of the efforts done for controlling STIs in Egypt focused on providing STIs services for high risk-populations like sex workers [21], [22]. Moreover, most PHC centers in Egypt do not provide any preventive programs for STIs because of lack of human and financial resources

Inthisstudy, a significantattitudinalimprovement toward STIs was observed in the post-intervention, which is consistent with findings reported by Sharma and Sherkhane [17]. Another study conducted in Egypt [9] reported that more than one third of participants agreed that they would seek treatment for their partner if they were diagnosed, while $15.2 \%$ reported that they would undergo a checkup in case their partners were infected and only $5.5 \%$ mentioned that they would ask for a divorce from their infected partner. In the current study, the effect of the adopted educational intervention was obvious in improving women's knowledge and attitudes toward STIs, in agreement with the findings reported by Sakha et al. [16].

In this study, healthcare providers were the most common source of information about STIs, newspapers and relatives/partners were the least. This finding could be attributed to low literacy rate, and the conservative Egyptian culture which does not allow discussing sensitive issue among relatives and partners, similar to that reported by Norbu et al. [19] but in contrast to another Indian study [23]. The finding that most of respondents had heard about STIs from healthcare providers suggested that STIs advocacy and education through them are efficient means for raising awareness. Furthermore, information and awareness on STIs can be promoted effectively through mass 
media as nearly half of women mentioned the media as a source of their knowledge, while more educated people can acquire more knowledge when exposed to different sources of information including electronic media (computer, Internet) and printed educational materials (books, newspapers, posters, booklets) [24]. Short message service or text messaging is becoming a popular form of communication, text messaging is widely available, inexpensive, and timely [25].

The findings of the current study should be viewed within the following limitations; first, the absence of a control group and using a single pre-post-test design with many built-in design flaws including maturation effect, history, and testing effect which may compromise internal validity. Second, the short follow-up period and lack of close monitoring were important limitations, longer follow-up provides a chance to evaluate the intermediate and long-term outcomes among women (health seeking and screening).

\section{Conclusion}

This study revealed low levels of STIs' knowledge before the educational intervention, significantly improved following intervention reflecting the urgent need for implementing educational programs to improve STIs' knowledge and increasing women's readiness for STIs screening.

\section{References}

1. World Health Organization. Global Incidence and Prevalence of Selected Curable Sexually Transmitted Infections-2008. Geneva: World Health Organization; 2012. Available from: http://www.who.int/reproductivehealth/publications/rtis/2008 sti_estimates.pdf. [Last accessed on 2018 Jul 15]. https://doi. org/10.1016/s0968-8080(12)40660-7

2. WHO Technical Paper. Regional Strategy for the Prevention and Control of Sexually Transmitted Infections 2009-2015 Regional Committee for the EM/RC55/6 Eastern Mediterranean; 2008.

3. Smith AC, Jones WP, Brown BP. Community health surveys. Arch Intern Med. 1996;26(8):201-7.

4. Amin TT. Sexually transmitted infections: The Egyptian situation with special emphasis on HIVIAIDS. Int Public Health Forum. 2014;1(3):6-13.

5. Bozicevic I, Riedner G, Calleja JM. HIV surveillance in MENA: Recent developments and results. Sex Transm Infect. 2013;89(3):iii11-6. https://doi.org/10.1136/ sextrans-2012-050849

PMid:23434789

6. Egypt Council of Ministers, Ministry of Planning. Strategy for Sustainable Development-Egypt Vision 2030; 2015.

7. Lan PT, Lundborg CS, Mogren I, Phuc HD, Chuc NT. Lack of knowledge about sexually transmitted infections among women in North Rural Vietnam. BMC Infect Dis. 2009;9:85. https://doi. org/10.1186/1471-2334-9-85

PMid:19500402

8. Chacko S, Kipp W, Laing L, Kabagambe G. Knowledge of and perceptions about sexually transmitted diseases and pregnancy: A qualitative study among adolescent students in Uganda. J Health Popul Nutr. 2007;25(3):319-27.

\section{PMid:18330065}

9. Bobhate PS, Shrivastava SR. A cross sectional study of knowledge and practices about reproductive health among female adolescents in an urban slum of Mumbai. J Family Reprod Health. 2011;5(4):117-24.

10. El Karaksy A, Eid MA, Zeidan A, Selim O, Fathy A, EIShafie $A$, et al. Awareness on sexually transmitted diseases among a sample of Egyptians. Hum Androl. 2013;3:54-8. tps:// doi.org/10.1097/01.xha.0000428122.74392.e6

11. Nasirian M, Karamouzian M, Haghdoost AA. Why is the number of HIVIAIDS-related publications low in the MENA region? Sex Transm Infect. 2014;89(3):iii10. https://doi.org/10.1136/ sextrans-2013-051199 PMid:23748677

12. Rosner B. Fundamentals of Biostatistics. $4^{\text {th }}$ ed. United States: Duxbury Press; 1995. p. 221.

13. Sekirime WK, Tamale J, Lule JC, Wabwire-Mangen F. Knowledge, attitude and practice about sexually transmitted diseases among University students in Kampala. Afr Health Sci. 2001;1(1):16-22.

PMid:12789128

14. Jaworski BC, Carey MP. Development and psychometric evaluation of a self-administered questionnaire to measure knowledge of sexually transmitted diseases. AIDS Behav. 2007;11(4):557-74. https://doi.org/10.1007/s10461-006-9168-5 PMid: 17016760

15. WHO. Department of Reproductive Health and Research (RHR), WHO. Sexually Transmitted and other Reproductive Tract Infections, a Guide to Essential Practice; 2017. Available from: http://www.who.int/reproductivehealth/publications/ rtis/9241592656/en. [Last accessed on 2019 Jun 05].

16. Fornasa CV, Gai F, Tarantello M, Gallina P. Knowledge of sexually transmitted diseases and condom use among female street sex workers in Padua. Acta Dermatovenerol Alp Pannonica Adriat. 2005;14(3):107-10.

PMid: 16200336

17. Sakha MA, Kazerooni PA, Lari MA, Sayadi M, Azar FE, Motazedian N. Effect of an educational intervention on knowledge, attitudes and preventive behaviours related to HIV and sexually transmitted infections in female sex workers in southern Iran: A quasi-experimental study. Int J STD AIDS. 2013;24(9):727-35. https://doi.org/10.1177/0956462413482424 PMid:23970587

18. Sharma $P$, Sherkhane MS. Knowledge and attitude about sexually transmitted infections among women in reproductive age group residing in the Urban Slums. Int $\mathrm{J}$ Community Med Public Health. 2017;4(1):20-4. https://doi.org/10.18203/23946040.ijcmph20164706

19. Nawagi F, Mpimbaza A, Mukisa J, Serwadda P, Kyalema S, Kizza D. Knowledge and practices related to sexually transmitted infections among women of reproductive age living in Katanga slum, Kampala, Uganda. Afr Health Sci. 2016;16(1):116-22. https://doi.org/10.4314/ahs.v16i1.15 PMid:27358621

20. Norbu K, Mukhia S, Tshokey T. Assessment of knowledge on sexually transmitted infections and sexual risk behaviour in two rural districts of Bhutan. BMC Public Health. 2013;13(1):1142. https://doi.org/10.1186/1471-2458-13-1142 
PMid:25292443

21. Sidig A, Mahgoub A, Hussein AA. Study of knowledge, attitude, practice towards HIVIAIDS and prevalence of HIVIAIDS among tea sellers women in Khartoum State. Sudan J Public Health. 2009;4(1):214-24.

22. Lal SS, Vasan RS, Sarma PS. Thankapan KR. Knowledge and attitude of college students in Kerala towards HIVIAIDS, sexually transmitted diseases and sexuality. Natl Med J India. 2000;13(5):231-6.

PMid:11190050

23. UNICEF, HIVIAIDS Egypt Profile; 2017. Available from: https:// www.unicef.org/egypt/hiv aids.html. [Last accessed on 2017 Jun 10].

24. Ruikar HA. Knowledge, attitude and practices about sexually transmitted infections-a study on Undergraduate College Students of Mumbai. Webmed Cent Reprod. 2013;4(3):WMC004166.

25. Bangladesh HIVIAIDS Update: Regional Update, South Asia Region (SAR)-Bangladesh, Reports of World Bank Group 2010. Available from: http://www.worldbank.org/en/news/ feature/2012/07/10/hiv-aids-bangladesh. [Last accessed on 2019 Oct 23]. 